\title{
Development of a sarcoma in a surgical scar
}

\author{
D.J. Sherlock, H. Rickards, T.I.M. Gardecki and J.D. Hamer \\ Department of Surgery, Queen Elizabeth Hospital, Edgbaston, Birmingham B17 2TQ, UK.
}

\begin{abstract}
Summary: The development of a malignant soft tissue tumour (malignant fibrous histiocytoma) in a surgical wound is reported. Although rare, this occurrence has important diagnostic implications and the management is discussed.
\end{abstract}

\section{Introduction}

Malignant fibrous histiocytoma (MFH) is a sarcoma of the deep soft tissues. It occurs predominantly in adults and is thought to originate from primitive mesenchymal cells. ${ }^{1}$ Although the cause of the malignant transformation is rarely known, there is an association with previous radiotherapy and occasionally the development of MFH has followed surgery or trauma.

We report a case of a MFH occurring in a recent cholecystectomy incision, and the subsequent management.

\section{Case report}

A 66 year old man presented with a painless lump developing at the lateral end of a subcostal incision performed 14 months previously for cholecystectomy. The operation had been performed for gallstones and was uneventful, the wound having been closed in layers using 'Vicryl' (Ethicon Ltd).

Initially, the lump was thought to be hypertrophic scarring associated with a persistent suture knot, but when he reattended a month later for exploration, the lesion had increased rapidly in size. The lesion was found to be firmly attached to the anterior rectus sheath, was $3 \mathrm{~cm}$ diameter and had a good blood supply. Microscopic examination demonstrated a giant cell type of histiocytoma with infiltration into surrounding tissue and there was neither macroscopic nor microscopic evidence of suture material.

At a second operation, a wide excision of all tissue within $5 \mathrm{~cm}$ of the initial lumpectomy margins was performed removing the adjacent costal margin, diaphragm and anterior rectus sheath. Reconstruction of the defect was performed using Marlex mesh (C.R. Bard Inc, MA), and skin cover was achieved with a

Correspondence: D.J. Sherlock M.S., F.R.C.S.

Accepted: 30 July 1987 rotational flap. The patient has now been followed up for 18 months without clinical evidence of recurrence and a computed tomographic scan of the region 1 year post-operatively failed to demonstrate deep local recurrence.

\section{Discussion}

The development of a MFH in a surgical wound is a cause of concern and diagnostic difficulty. The reported case is unusual in both the rarity of the condition and rapidity of development.

Malignant fibrous histiocytoma is a soft tissue sarcoma containing various proportions of both histiocytic and fibroblastic cell types, usually arranged in a whorl accompanied by both pleomorphic giant cells and inflammatory cells. ${ }^{1}$ It is commonest in late adult life and typically occurs on the extremities or retroperitoneum; the anterior abdominal wall is an unusual site. The tumour usually presents as a painless lump, accompanied by general malaise and weight loss when large.

Radiation-induced MFH is well documented ${ }^{1-3}$ and there have been reports of its occurrence following both trauma and infarcts in bone. ${ }^{3}$ In 200 cases of MFH, Weiss and Enzinger reported two cases following radiotherapy but found only one example in which this lesion had developed in a surgical scar - the site of excision of a lipoma 8 years previously.' Inoshita and Youngberg described two cases of MFH developing in surgical wounds - one 6 years after an above knee amputation and the other 2 years following inguinal herniorrhaphy ${ }^{3}$ and a thermal burn has also been associated with development of MFH. ${ }^{5}$ Apart from the evidence of ongoing chronic inflammation with the presence of giant cells containing suture material, no exact understanding of the pathophysiology of the malignant transformation is understood.

Wide excision of these tumours is necessary as the lesion is covered with a dense pseudocapsule outside 
which tumour extends into adjacent tissues. Local excision is accompanied by a $100 \%$ recurrence rate. ${ }^{4}$

The results following surgery are not encouraging; nearly two thirds of patients develop local or distant spread to the regional lymph nodes and lungs. This can occur at a very variable period following surgery and, of these patients, half will eventually succumb of the

\section{References}

1. Weiss, S.W. \& Enzmger, F.M. Malignant fibrous histiocytoma: an analysis of 200 cases. Cancer 1978, 41: 2250-2266.

2. Kim, J.H., Chu, F., Woodward, H. et al. Radiation induced soft tissue and bone sarcomas. Radiology 1979, 129: 501-508.

3. Inoshita, T. \& Youngberg, G. Malignant fibrous his- disease within 2 years. ${ }^{1}$ Neither radiotherapy nor chemotherapy appear to be of any value. ${ }^{4}$

The occurrence of MFH in a surgical wound poses questions as to the aetiology of malignant change and its balance with the healing response. Although rare, an increased awareness of this association may improve the prognosis in this group of patients.

tiocytoma arising in a previous surgical site. Report of two cases. Cancer 1984, 53: 176-183.

4. Lattes, R. Malignant fibrous histiocytoma. Am J Surg Pathol 1982, 6: 761-771.

5. Gaynar, W. \& DeLaschmutt, R. Malignant mesenchymoma arising in the scar of a thermal burn. Am J Clin Pathol 1957, 28: 74-77. 